\title{
The Possible Challenges of Adoption of International Financial Reporting Standards: A Qualitative Meta-analysis Approach
}

\author{
Abebe Gibru ${ }^{1, *}$, Mezgebu Aynalem² \\ ${ }^{1}$ Department of Accounting and Finance, Debre Markos University, Burie Campus, Burie, Ethiopia \\ ${ }^{2}$ Department of Agri-Business and Value Chain Management, Debre Markos University, Burie Campus, Burie, Ethiopia \\ Email address: \\ abebegibru@gmail.com (A. Gibru),mezgebu12aynalem@gmail.com (M. Aynalem) \\ ${ }^{*}$ Corresponding author
}

To cite this article:

Abebe Gibru, Mezgebu Aynalem. The Possible Challenges of Adoption of International Financial Reporting Standards: A Qualitative Metaanalysis Approach. Journal of Investment and Management. Vol. 8, No. 6, 2019, pp. 86-93. doi: 10.11648/j.jim.20190806.11

Received: September 9, 2019; Accepted: October 29, 2019; Published: January 6, 2020

\begin{abstract}
Currently, International Financial Reporting Standards (IFRS) have been adopted by over 143 countries all over the world. The aims of this standard is to develop, in the public interest, a single set of high-quality, comprehensible, enforceable and globally accepted financial reporting standards based on clearly expressed principles and legislations. Nevertheless, its adoption procedure creates challenges to the adopter. Thus, the purpose of this study was to investigate the possible challenges of adoption of international financial reporting standards (IFRS). A sample of fifteen studies and articles related to challenge of International Financial Reporting Standards adoption that had been done starting from 2012 were selected from journal articles; Master of Science thesis (MSC) and master of business administration (MBA) thesis, then the collected data were analyzed using qualitative meta- synthesis which is presented using tables and narratives. The study found out that cost of adoption, training of relevant accounting professional, lack of competent man power, lack of proper financial reporting guidance, use of fair value accounting in comparison to historical cost method, Lack of proper instructions from regulatory bodies, increases the risk for handling in interpretation of financial statements and modernized information technology system in handling the transitions to standard were the main challenges of International Financial Reporting Standards adoption.
\end{abstract}

Keywords: IFRS, Regulatory Bodies, Challenge of IFRS

\section{Introduction}

\subsection{Background of the Study}

The procedure of financial reporting of most business activities undertook a great change over the last few decades of recent years. In relation to this, most countries of the world have transformed their accounting practices especially during the last few decades of the 21 century. Such transformation incorporates the adoption and adaptation of local accounting practices and harmonizing it with that of the International Financial Reporting Standards (IFRS) formerly International Accounting Standards (IAS). This revolution, as it is evidenced, is started in 2002 when European Union made it mandatory for publicly traded companies to present consolidated financial statements in conformity with International Financial Reporting Standards starting from January 01, $2005[1,2]$.

IFRSs are a set of accounting principles that is rapidly gaining acceptance on a worldwide basis. They are published by International Accounting Standards Board (IASB) which based in London. It is more focused on objectives and principle based. They purport to be a set of rules that ideally would apply equally to financial reporting by public companies worldwide. The adoption of IFRS as issued by the International Accounting Standards Board (IASB) is expected to effect in the application of a common set of financial reporting standards within and between countries in Europe and many other countries that require or permit application of IFRS. However, according to the 
study of [3,4] and [5], comparability is unlikely to arise from IFRS adoption they also concludes that internationalization will reduce some or much of the diversity in accounting rules and practices across nations, it will not eliminate it, nor should it". Specifically, [3] expresses concerns that the application of IFRS will not be uniform and that this will affect the reporting and perception of IFRS quality by users.

Many researchers have dig out about the advantage of adopting IFRS. For instance, [6] advocated that adoption of IFRS will lead to: greater transparency and understandability, decrease cost of capital to companies and increased share prices (as a result of greater confidence of investors and transparent information), reduced national standard-setting costs, ease of regulation of securities markets, easier comparability of financial data across borders and investment opportunities, increased credibility of domestic markets to foreign capital providers and potentials foreign merger partners, and to potential lenders of financial statements from companies in less-developed countries. Additionally, it will also facilitate easier international mobility of professional staffs across national boundaries. For the multinational companies, it will help them to fulfill the disclosure requirement for stock exchanges around the world [7, 8]. Other benefits, as concluded by [9], include: the lower susceptibility to political pressures than national standards, continuation of local implementation guidance for local circumstances and the tendency for accounting standards to be raised to the highest possible quality level throughout the world. Furthermore, a study conducted by [6] reveals that investors expected net benefits to IFRS adoption in Europe associated with increases in information quality, decreases in information asymmetry, more rigorous enforcement of the standards, and convergence. Besides, [10] disclosed the benefits from adaptation of IFRS over the world to include: better financial information for shareholders and regulators, improved comparability, improved transparency of results, increased ability to secure cross-border listing, better management of global operations and decreased cost of capital.

According to the study done by [5], countries wishing to adopt IFRS suggest six bases for decision as: contribution to prosperity and wealth of society, inclusion of relevant information from all parts of the economy, stability over time, adaptability to changes in economic environment, robustness against manipulations, and resistance to capture by narrow interest groups. To this regard, the need to have quality financial reports and other benefits such as its ability to significantly increase the comparability of entities, giving better access to global capital markets and reduced cost of capital, and provision of motivation to cross border acquisitions that the adoption of International Financial Reporting Standards is becoming trend among countries [11,12].

Even though IFRS has the potential for facilitating crossborder comparability, increasing reporting transparency, decreasing information costs, reducing information asymmetry and thereby increasing the liquidity, competition and efficiency of markets, cultural, political and business differences may also continue to impose significant obstacles in the progress towards a single global financial communication system because a single set of accounting standards cannot reflect the differences in national business practices arising from differences in institutions and cultures $[3,6,13]$. Moreover, as concluded by [14], the main hindering factors in the adoption process of IFRS in Europe, America and the rest of the world are not necessarily technical but cultural issues, mental models, legal impediments, educational needs and political influences.

\subsection{Statement of the Problem}

Many of the advocator of IFRS claims that IFRS have advantages over local accounting standards for several reasons. Firstly, according to [15], IFRS may be more capital-oriented to investors. Secondly, as concluded by [16, 17] it can reduce the choice of accounting methods, constraining managerial discretion. Thirdly, as revealed by [18]; it require accounting measurements recognition that better reveal a firm's underlying economic position, hence providing information for investment decisions. Fourthly, it required disclosures, thereby alleviating information asymmetries between firm's shareholders [16]. Aside from financial reporting quality argument, proponents of IFRS also claim that harmonization IFRS increases comparability of firms across markets and countries, hence facilitating investment and integration of capital markets [6].

In light of these potential advantages, as concluded by European Council (2002), proponents of IFRS often argue that they can be for investors, issuers, and economies because enhanced financial reporting can result investor demand for equities and lower cost of capital. Theory that these outcomes will follow if (1) market liquidity increases and price protection lower information asymmetries among investors [19]; (2) risk sharing improves due to increased awareness of investment opportunities by [20]; or (3) the estimation risk facing investors falls [21]. In each case investment portfolio decisions depend on financial reporting, and a change to a higher quality homogeneous financial reporting regime is predicted to result in an increase in demand and investment holdings.

Several survey studies have been conducted to assess the adoption of International Financial Reporting Standards in different countries of the world. A number of studies have been conducted in relation to the importance [12]. The other set of studies have been done on the effect IFRS has on companies and countries at large [1].

The above-mentioned and other studies had been conducted to assess the adoption of International Financial Reporting Standards in different countries. Since European Union (EU) was the first to adopt IFRS across the globe, most of the research has been conducted on IFRS analyzing the data from member countries of EU.

This study was, therefore, motivated because of the absence of review of studies in the area of IFRS adoption, as per the researcher's knowledge, challenges and factors that could explain its adoption. This paper is intended to address 
the following research question.

What are the possible challenges of IFRS adoption?

\subsection{Objective}

The general objective of this review study is to investigate the possible challenges of IFRS adoption.

\section{Methodology}

\subsection{Research Design}

This study used qualitative meta-synthesis analysis to address the research questions focusing on previous research carried out on challenges of adopting IFRS in the last eight years. Even if there are some critics over the application of meta-analysis such as lack of standardized rule about how to generalize from individual results for a particular research topic, it allows more accurate data analysis relative to narrative reviews. To this end, the study intended to examine through and sort data with respect to research designs, tools of data gathering, findings, and implications for further research.

\subsection{Data Sources}

In order to accomplish the intended objective of the article, the researcher had viewed various studies and articles related to challenge of IFRS adoption that had been done starting from 2012. Specifically, secondary data were taken from journal articles (JA), Master of Science thesis (MSC) and master of business administration (MBA) theses.

\subsection{Selection of Studies}

For studies to be included in this meta-analysis, it had to be a significant helpful events and criteria. To identify which studies have to be part of the Meta analysis, the researcher had viewed articles, journals and senior studies about the challenge of IFRS adoption. Thus, the researcher had screened out based on title, the time of conduction and research questions. Accordingly, 15 (fifteen) studies had been included which were done from 2012 up to 2018 as presented in table 1 . The reason behind this time frame is that due to time constraint to review all sources, recentness of sources, availability and aim of the study. Those are presented as follows.

Table 1. Selection of studies.

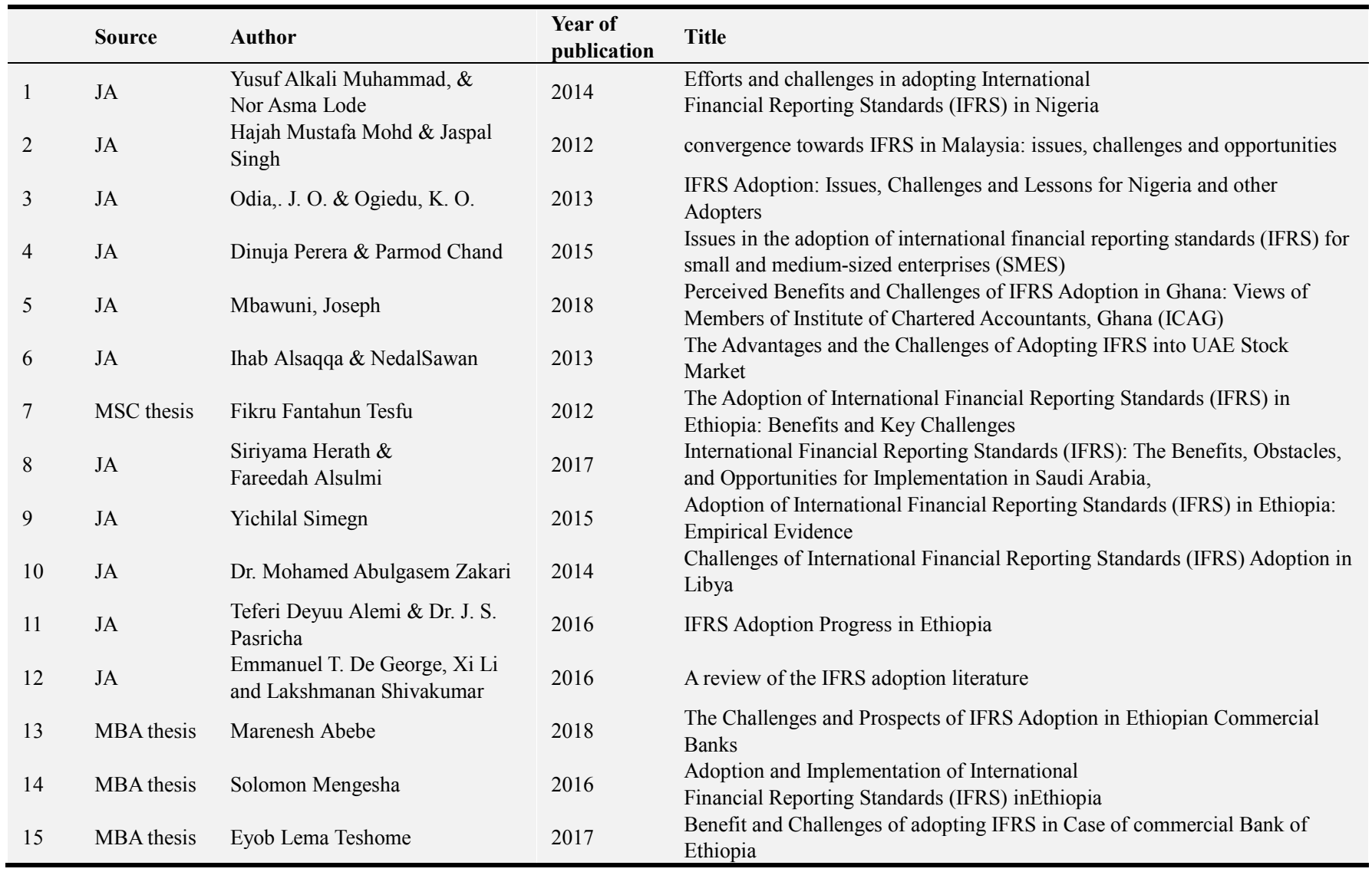

\section{Results}

Once the data were gathered from articles, MSC thesis and MBA thesis, a clustering of those data were undertaken by the researcher. Clustering of studies was according to the type of research design, source of data, tool of data gathering finding of the individual studies and implication for further researches. Accordingly, the following table summarizes main components of each sample studies including country under which the study had been conducted. 


\subsection{Clustering via Research Design, Tool of Data Gathering, Data Source, and Finding}

Table 2. Clustering via research design, tool of data gathering, data source, and finding.

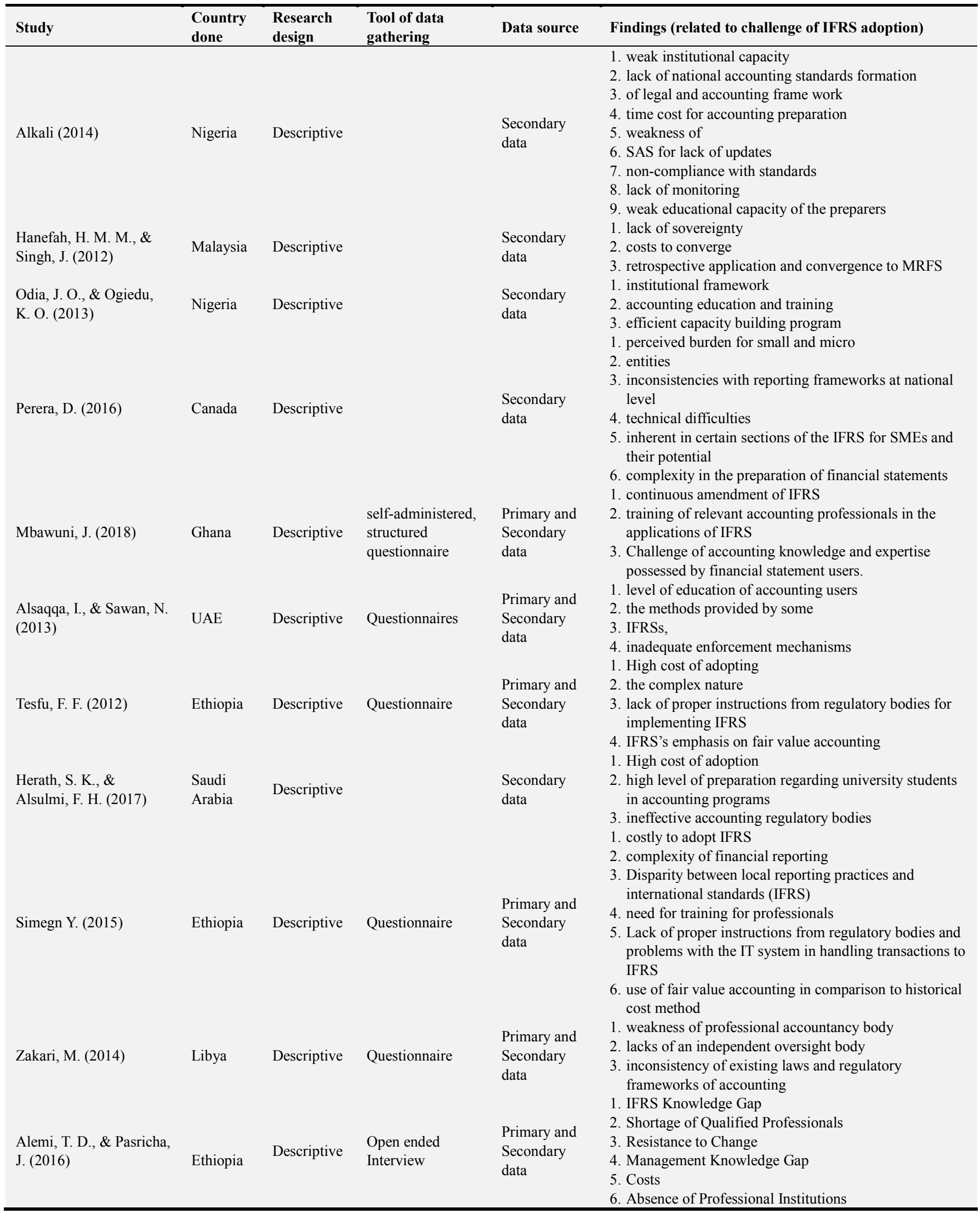




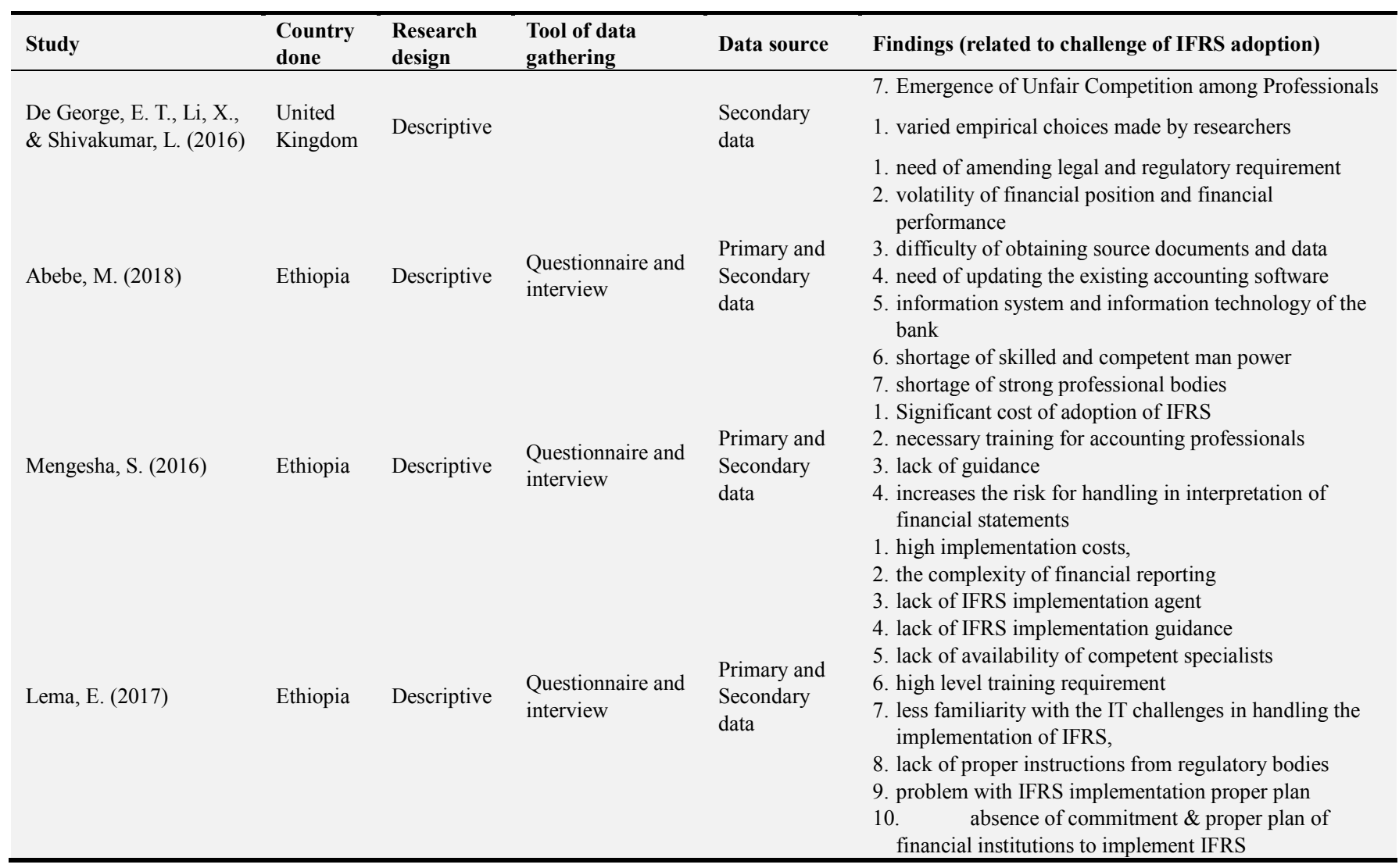

As disclosed from the above table 2, selected studies were conducted from different part of the world including in Africa such as [9, 22-30]: Asia such as [31-34]: Europe such as [35]. So, taking studies which were conducted in various countries and continent enabled the researcher to draw a broad conclusion about major challenge faced while adopting IFRS. Since it is a global issue, reviewing of researches that were conducted all over the world can enable to identify prominent challenges while adopting those single set of qualified standards. As a result, countries on the road of adopting IFRS can able to catch up those challenges and smoothly adopt it without facing such extreme bottlenecks.

All studies in the above table used descriptive design research approach. Thus, what described is that major challenges will a country face in the process of convergence of locally used accounting standard to single set of qualified global accounting standard (IFRS). The appropriateness of such researches has been explained that they describe already challenges in the way of their convergence.

In order to found out and attained their research objective, all selected studies used secondary data sources. Those data were gathered through document review maintained by the companies prior to the full adoption of the standard. As those studies reveals, especially public interest companies had data, even if it is not well organized as needed, which helps to identify those challenge. Thus, all used the the sources available to capture the challenges. In addition, most researches such as $[23-30,34]$ had employed primary data which was collected through various survey methods. For triangulation purpose, usage of primary data with secondary data is appreciated that can enable the researchers to identify the leading hindering factors that can face against the adoption process. Especially, most stakeholders of sampled organization of studies had greater information about why the convergence of locally accepted principles to the international one is worthwhile. In so doing, they can easily find out and tackle the problems. Such information from them can be collected through questionnaire and interviews that is why most of them used as gathering instrument.

The above tabular presentation of challenges of IFRS adoption, as shown in the above, also enables the researcher to make a conceptual generalization about finding of each study. Thus most of the studies had identified high cost of adoption as main challenge is the process of IFRS adoption $[22,24,25,27,29,30,32]$. The adoption procedure of the standard should strengthen various institutions which will enhance its effective implementation of the standards such as: CPA firms and enforcers such as auditors, legal systems and courts regulators, shareholders, law-makers, analysts, rating agencies, accounting professional bodies, tax authorities and capital market regulators, corporate governance structure, the press, public, educational institutions and business schools, financial market. All the aforementioned bodies need to aware about the application of the standard by including all activities that bounce from adoption. Thus, it requires the incurrence of potential resources which is the main challenge.

Next, training of relevant accounting professionals in the applications of IFRS and lack of competent man power in the area of accounting were described as challenge for countries 
convergence to global accounting standard [9, 22, 23, 25-30, $33,34]$. In order to effectively adopt, there is increased demand for training and education for selected users such as investors, accountants, auditors, preparers and users of financial reports. Moreover, the devising of IFRS curricula at the university and other educational levels can be taken as the best way for the road of convergence. However, as most of the research work supports, little is done on inclusiveness within the curriculum. The legal system must also be familiar with the new IFRS standards as it applies to forensic accounting, tax issues, auditing and other aspects of accounting laws.

\subsection{Clustering of Studies is Done via Future Research Implications}

Another clustering of studies is done via future research implications that given by each researchers. Thus, the following table recaps implication of each study.

Table 3. Implication for further research.

\begin{tabular}{|c|c|}
\hline Study & Implication for further research \\
\hline Alkali (2014) & investigate the impact of IFRS on the quality financial reporting under two regimes (Pre and Post of IFRS) \\
\hline Hanefah, H. M. M., \& Singh, J. (2012) & - \\
\hline Odia, J. O., \& Ogiedu, K. O. (2013) & - \\
\hline Mbawuni, J. (2018) & $\begin{array}{l}\text { 1. provide comparative analysis of perceived benefits and challenges of IFRS adoption in multiple countries in } \\
\text { Sub-Saharan African in order to enhance our understanding of similarities and differences in IFRS adopt }\end{array}$ \\
\hline Alsaqqa, I., \& Sawan, N. (2013) & - \\
\hline Tesfu, F. F. (2012) & $\begin{array}{l}\text { 1. issue of disclosure and compliance with IFRS in Ethiopia } \\
\text { 2. mandatory IFRS adoption affects financial statements } \\
\text { 3. How small and medium scale enterprises adopt and comply with IFRS } \\
\text { 4. factors affecting the adoption of IFRS by Ethiopia }\end{array}$ \\
\hline Herath, S. K., \& Alsulmi, F. H. (2017) & $\begin{array}{l}\text { 1. the impact of IFRS on improving bank performance } \\
\text { 2. research reviewing the extent that environmental factors influence the way IFRS is applied } \\
\text { 3. studies that illustrate the banking and insurance performance, before and after IFRS implementation } \\
\text { 4. Conduct research and devise an appropriate classification system for reporting Zakat using international } \\
\text { standards. } \\
\text { 5. find a way to make the guidance of IFRS fit within their respective cultural framework }\end{array}$ \\
\hline Simegn Y. (2015) & - \\
\hline Zakari, M. (2014) & - \\
\hline Alemi, T. D., \& Pasricha, J. (2016) & - \\
\hline $\begin{array}{l}\text { De George, E. T., Li, X., \& Shivakumar, } \\
\text { L. (2016) }\end{array}$ & - \\
\hline Abebe, M. (2018) & - \\
\hline Mengesha, S. (2016) & $\begin{array}{l}\text { 1. issue of disclosure and compliance with IFRS in Ethiopia } \\
\text { 2. how mandatory IFRS adoption affects financial statements } \\
\text { 3. How small and medium scale enterprises adopt and comply with IFRS }\end{array}$ \\
\hline Lema, E. (2017) & $\begin{array}{l}\text { 1. Benefit and challenges of IFRS adoption in governmental, microfinance financial institutions and other } \\
\text { private Banks in Ethiopia. } \\
\text { 2. effective implementation of IFRS in Ethiopia }\end{array}$ \\
\hline
\end{tabular}

As shown from the above table most of them provides an implication for further research areas. Once a study is done on a certain topic and delivers its main finding, it should also indicate further areas related to the topic mostly not covered by the study undertaken. Indicating implications of research may be two ways: for further researchers and for practical applicability [36]. In this aspect, among the fifteen selected studies only seven $[22-24,29-31,33]$ had clearly shown implication of their study for further researcher. They strongly advised future researchers to conduct a study on disclosure and compliance issues related to IFRS adoption and its effect on financial statement especially studies done on Ethiopia. It is also indicated that performing study on performance of a business before and after the adoption of IFRS is another area of research. Moreover, researches noticed that challenge, prospect and benefit of IFRS adoption should be studied by increasing its scope.
A study conducted by [37] suggested that new researches can be done with some improvement. The improvements may include revision and administration of the questionnaire at the state, regional and national levels, terminology identification and clarification in the questionnaires.

Thus, further researchers can conduct study on this area by extending the content of the study to other areas even the researcher himself.

\section{Conclusion}

This qualitative meta-analysis of fifteen research studies conducted on IFRS adoption in last eight years suggests the following guidelines.

Cost of adoption of IFRS was the prominent challenge that most of the selected studies had found out. It consists of cost of time devoted to adopt and resource used while thereof. 
Countries attempting adoption of IFRS should schedule time when it will converges including mandatory adoption period and amount of resource needed for the process.

In the way of adoption, there should be a competent man power who can apply his / her knowledge and skill for making effective and efficient adoption unless it may take long time and need training of the professionals. This was what most of the studies has indicated the second challenge. Thus, for countries which had no local accounting standard such as Ethiopia, accounting professionals ought to have theoretical as well as practical knowledge.

Once a country adopts it needs continuous amendment of IFRS. This amendment depends on accounting knowledge and expertise possessed by financial statement preparers and users. This, in addition, is taken as another challenge.

Effective adoption of IFRS requires a proper coordination of concerned bodies especially organized within the border of the counties. It should bestow sufficient time table or road map for the organizations starting from public interest companies to small and medium size enterprises. The communications system for informing bodies of the changes in reporting requirements had better effective and responsive. Users of financial statements such as creditors, investors', regulators and others should have to be able to interpret financial reports and nurture questions about an entity's performance. Thus, what refrain from efficient and effective adoption is the lack cooperativeness between concerned stakeholders.

For effective adoption of this standard inevitably require competent and qualified manpower in the area of account and finance. Thus, the prevalence of this knowledge gap within the concerned parties has become one of the prominent challenges. In most developing countries there are less number of accountants and auditors who are qualified in ACCA which may enable them to fill knowledge. Even if governmental agencies provides a support for participant of this affiliate, still there is a shortage of those individual who can strive for accomplishing the qualification, in turn, which can lessen challenge.

\section{References}

[1] Jermakowicz, E. K., Effects of adoption of international financial reporting standards in Belgium: the evidence from BEL-20 companies. Accounting in Europe, 2004. 1 (1): p. 5170 .

[2] Putrayasa, I. B. and A. Susana, Kalimat efektif: (diksi, struktur, dan logika). 2007: Refika Aditama.

[3] Ball, R., A. Robin, and G. Sadka, Are timeliness and conservatism due to debt or equity markets? An international test of "contracting" and "value relevance". Theories of Accounting. Manuscript, University of Chicago, 2006.

[4] Christensen, H. B., et al., Incentives or standards: What determines accounting quality changes around IFRS adoption? European Accounting Review, 2015. 24 (1): p. 31-61.

[5] Sunder, S., IFRS Monopoly: The Pied Piper of Financial
Reporting, being paper prepared for information for better markets conference ICAEW. London December, 2010: p. 2021.

[6] Armstrong, C. S., et al., Market reaction to the adoption of IFRS in Europe. The accounting review, 2010. 85 (1): p. 31-61.

[7] Covrig, V. M., M. L. Defond, and M. Hung, Home bias, foreign mutual fund holdings, and the voluntary adoption of international accounting standards. Journal of Accounting Research, 2007. 45 (1): p. 41-70.

[8] Daske, H., et al., Adopting a label: Heterogeneity in the economic consequences around IAS/IFRS adoptions. Journal of Accounting Research, 2013. 51 (3): p. 495-547.

[9] Odia, J. and K. Ogiedu, IFRS adoption: Issues, challenges and lessons for Nigeria and other adopters. Mediterranean Journal of Social Sciences, 2013.4 (3): p. 389.

[10] Gordon, I. M., Lessons to be learned: An examination of Canadian and US financial accounting and auditing textbooks for ethics/governance coverage. Journal of Business Ethics, 2011. 101 (1): p. 29-47.

[11] Baker, C. R. and E. M. Barbu, Trends in research on international accounting harmonization. The International Journal of Accounting, 2007. 42 (3): p. 272-304.

[12] Iyoha, F. and O. S. Faboyede, Adopting International Financial Reporting Standards (IFRS) - A Focus on Nigeria. International Journal of Research in Commerce and Management, 2011.2 (1).

[13] Soderstrom, N. S. and K. J. Sun, IFRS adoption and accounting quality: a review. European Accounting Review, 2007. 16 (4): p. 675-702.

[14] Obazee, J., Current Convergence Efforts in Accounting Standard Setting and Financial Reporting: Lagos, Nigerian Accounting Standing Board. January, 2007. 31: p. 17-26.

[15] Hail, L., C. Leuz, and P. D. Wysocki, Global accounting convergence and the potential adoption of IFRS by the United States: An analysis of economic and policy factors. Available at SSRN 1357331, 2009.

[16] Ashbaugh, H. and M. Pincus, Domestic accounting standards, international accounting standards, and the predictability of earnings. Journal of accounting research, 2001.39 (3): p. $417-$ 434.

[17] Barth, M. E., W. R. Landsman, and M. H. Lang, International accounting standards and accounting quality. Journal of accounting research, 2008. 46 (3): p. 467-498.

[18] Ojeka, S. and D. Mukoro, internationa financial reporting standard (ifrs) and smes in nigeria: perception of academic. International journal of research in commerce \& manp., gement, 2011.2 (1): p. 13-19.

[19] Baiman, S. and R. E. Verrecchia, The relation among capital markets, financial disclosure, production efficiency, and insider trading. Journal of accounting research, 1996. 34 (1): p. $1-22$.

[20] Easley, D. and M. O'hara, Information and the cost of capital. The journal of finance, 2004. 59 (4): p. 1553-1583.

[21] Lambert, R., C. Leuz, and R. E. Verrecchia, Accounting information, disclosure, and the cost of capital. Journal of accounting research, 2007. 45 (2): p. 385-420. 
[22] Alkali, M. Y. and N. A. Lode, Efforts and Challenges in Adopting International Financial Reporting Standards (IFRS) in Nigeria.

[23] Mbawuni, J., Perceived Benefits and Challeges of IFRS Adoption in Ghana: Views of Members of Institute of Chartered Accountants, Ghana (ICAG). International Journal of Financial Research, 2018.9 (1): p. 99-114.

[24] Tesfu, F. F., The Adoption of International Financial Reporting Standards (IFRS) in Ethiopia: Benefits and Key Challenges. MSC Research Paper, 2012.

[25] Simegn, Y., Adoption of International Financial Reporting Standards (IFRS) in Ethiopia: Empirical Evidence. The International Journal Research Publication's Research Journal of Economics and Business Studies, 2015. 4 (3).

[26] Zakari, M., Challenges of International Financial Reporting Standards (IFRS) Adoption in Libya. International Journal of Accounting and Financial Reporting, ISSN, 2014: p. 21623082 .

[27] Alemi, T. D. and J. Pasricha, IFRS Adoption progress in Ethiopia. Research Journal of Finance and Accounting, 2016. 7 (1): p. 69-81.

[28] Abebe, M., The Challenges and Prospects of IFRS Adoption in Ethiopian Commercial Banks. 2018: GRIN Verlag.

[29] Mengesha, S., Adoption and Implementation of International Financial Reporting Standards (IFRS) in Ethiopia. 2016, St. Mary's University.
[30] Lema, E., Benefit and Challenges of adopting IFRS in Case of commercial Bank of Ethiopia Addis Ababa, Ethiopia. 2017, St. Mary's University.

[31] Perera, D., Adoption of international financial reporting standards (IFRS) for small and medium-sized enterprises (SMEs): problems and challenges. 2016.

[32] Hanefah, H. M. M. and J. Singh, Convergence towards IFRS in Malaysia: Issues, challenges and opportunities. International Journal of Business, Economics and Law, 2012. $1(2)$ : p. 85-91.

[33] Herath, S. K. and F. H. Alsulmi, International Financial Reporting Standards (IFRS): The Benefits, Obstacles, and Opportunities for Implementation in Saudi Arabia. International Journal of Social Science and Business, 2017. 2 (1): p. 1-18.

[34] Sawan, N. and I. Alsaqqa, The advantages and the challenges of adopting IFRS into UAE stock market. International Journal of Business and Management, 2013. 8 (19): p. 1-23.

[35] De George, E. T., X. Li, and L. Shivakumar, A review of the IFRS adoption literature. Review of Accounting Studies, 2016. 21 (3): p. 898-1004.

[36] Aydın, N., Teaching Shakespeare: A qualitative meta-analysis. 2013, Bilkent University.

[37] Viccellio, P., FISCAL IMPACT: Budgeted committee and staff resources. 